John Kiyaya. Photographe tanzanien et les gens du Lac Tanganyika

Dar es Salaam: Mkuki na Nyota, 2013

Marie-Aude Fouéré

\title{
OpenEdition
}

Journals

Édition électronique

URL : https://journals.openedition.org/eastafrica/370

DOI : 10.4000/eastafrica. 370

ISSN : 2790-1076

Éditeur

IFRA - Institut Français de Recherche en Afrique

Édition imprimée

Date de publication : 1 septembre 2014

Pagination : 198

ISSN : 2071-7245

Référence électronique

Marie-Aude Fouéré, « John Kiyaya. Photographe tanzanien et les gens du Lac Tanganyika », Les Cahiers d'Afrique de l'Est / The East African Review [En ligne], 49 | 2014, mis en ligne le 07 mai 2019, consulté le 09 décembre 2021. URL : http://journals.openedition.org/eastafrica/370 ; DOI : https://doi.org/ 10.4000/eastafrica.370

Ce document a été généré automatiquement le 9 décembre 2021.

Les Cahiers d'Afrique de l'Est / The East African Review 


\section{John Kiyaya. Photographe tanzanien et les gens du Lac Tanganyika}

Dar es Salaam: Mkuki na Nyota, 2013

Marie-Aude Fouéré

1 Un ouvrage unique rassemblant une série de photographies de John Kiyaya, photographe tanzanien découvert et soutenu par Jean Rolin. Avec des textes de John Kiyaya, Jean Rolin, Alain Ricard, Kapwani Kiwanga, François Bart, et un entretien entre John Kiyaya et Walter Bgoya, directeur de la maison d'édition Mkuki na Nyota, le tout en français, en anglais et en swahili, ce qui est une très belle performance. Ces photographies, principalement des portraits et des scènes de vie pris sur le vif ou posés, illustrent le quotidien des villageois et des pêcheurs du sud du lac Tanganyika, la région d'origine de Kiyaya. Comme l'indique François Bart (p. 34), «(l)es photographies de John Kiyaya révèlent des hommes et des paysages, des hommes dans des paysages » dans une Tanzanie rurale et laborieuse, tout à la fois moderne et traditionnelle.

\section{INDEX}

Index géographique : Tanzania | Tanzanie 